\title{
Histiocytosis presenting as swelling of orbit and eyelid
}

\author{
B. W. GODLING, K. G. SONI, D. R. BARRY, AND
} W. MARTIN-WALKER

From the Department of Pathology, University of Birmingham, and the Birmingham and Midland Eye Hospital

This paper describes the clinical investigation, and light and electron microscope findings in a Pakistani girl who developed bilateral orbital and eyelid swellings in association with lymphadenopathy. The findings do not correlate with any of the previously recognized causes of these symptoms although similarities with some of the lymphoreticular disorders, in particular Hand-Schüller-Christian disease and the recently described sinus histiocytosis with massive lymphadenopathy (Rosai and Dorfman, I969) are present.

The nature of the condition and its differential diagnosis and treatment are discussed.

\section{Case history}

An Ir-year-old Pakistani girl, who was born in Birmingham but subsequently visited Pakistan, presented in April, 1970, with recurrent eyelid swellings and progressive proptosis. She also complained of irritation and inability to close the left eye and recent onset of increasing deafness.

Similar lid swellings had previously been excised in 1962 and 1966 at the Queen Elizabeth Hospital, Birmingham, when she was aged 3 and 7 years respectively.

Apart from these complaints the patient was well, having no history of fever, ear discharge, or loss of weight or appetite.

Two other members of the patient's family (Fig. I), in which first-cousin marriages are common,

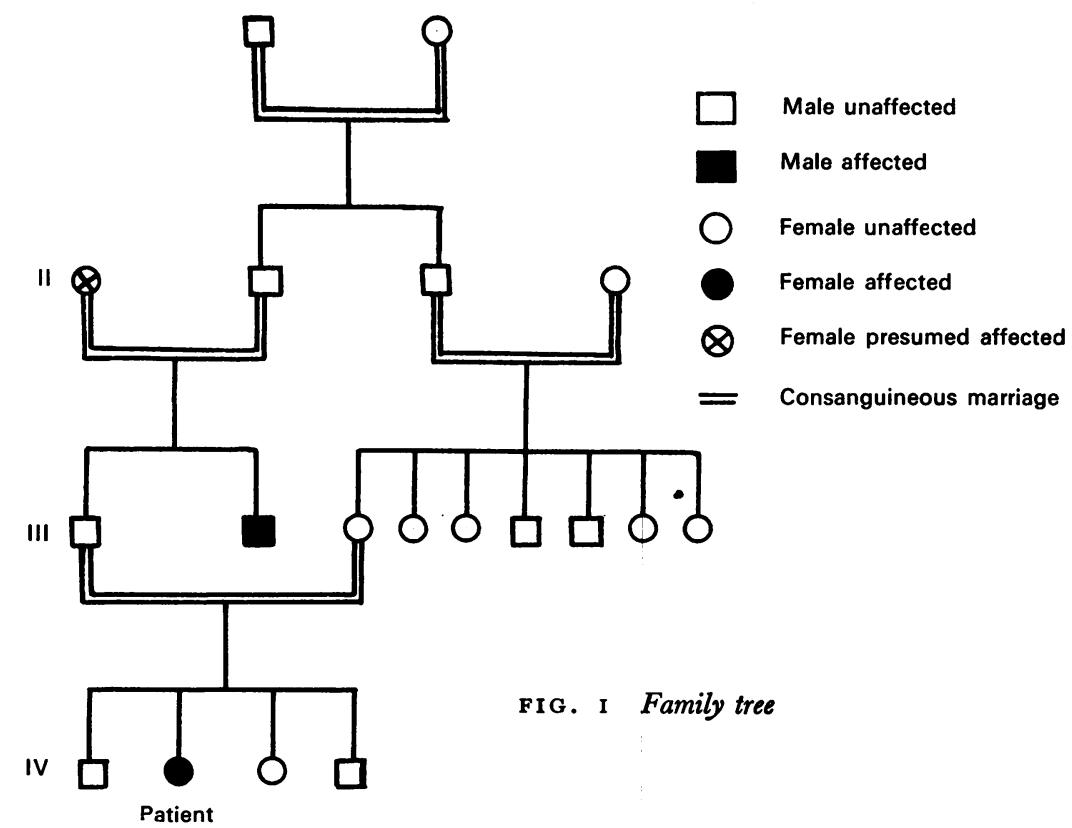


(2a)

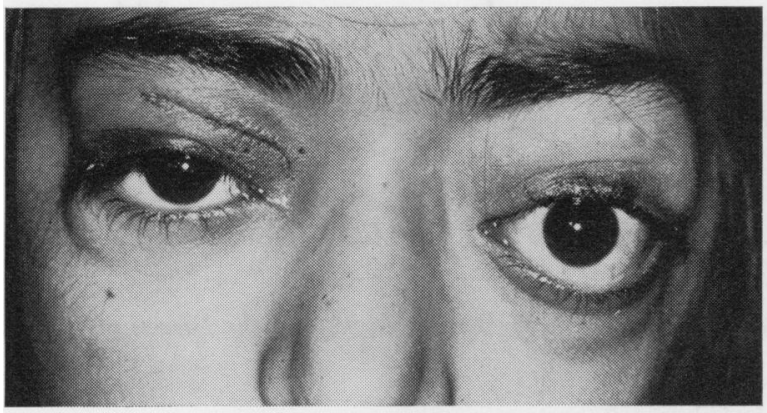

II G. $2(a, b)$ Frontal and lateral viezes of orbital and eyelid tumours after biopsy of right upper eyelid swelling. April 23, 1970

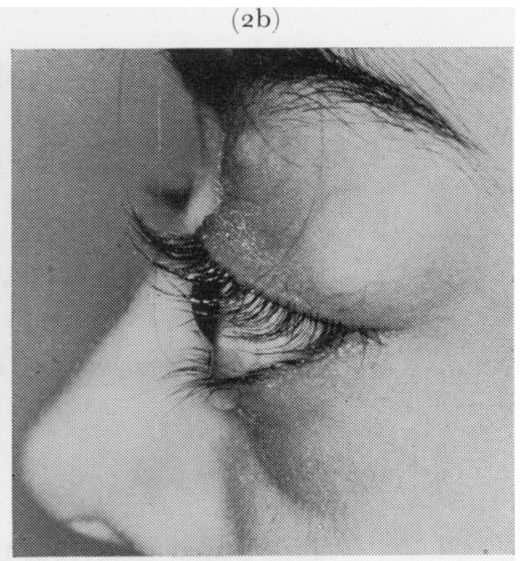

the paternal uncle and grand-mother, also had recurrent lid swellings and deafness. The uncle, who is alive and lives in Pakistan, has had operative treatment for the lid swellings. The grandmother died after a postpartum haemorrhage at the age of 40 .

An older brother of the patient was spastic due to birth trauma and died at the age of ${ }_{1} 5$ months from an unknown cause. A brother and sister are alive and well.

The patient was a slightly built pale girl of average intelligence showing firm rubbery masses in the upper and lower lids of both eyes (Fig. 2a,b). These were circumscribed and not adherent to the skin or underlying tissues. The swellings in the right upper lid were confined to the inner half of the lid and measured $1.5 \mathrm{~cm}$. in diameter; in the right lower lid the swelling was in the lateral third of the lid and measured $\mathrm{I} \mathrm{cm}$. in diameter. On the left side the swelling in the upper lid measured $\mathrm{I} \cdot 5 \mathrm{~cm}$. and in the lower lid $0.75 \mathrm{~cm}$. in diameter. Orbital swellings were also present; these were adherent to the roof of the orbit and the posterior limit could not be defined. These swellings caused bilateral proptosis, more marked on the left where lid closure was inadequate (Hertel Exophthalmometer reading $R 22 \mathrm{~mm}$., $L 29 \mathrm{~mm}$.). The visual acuity was $6 / 9$ in each eye and no oculomotor deficiency was present. The fundi were normal. The cervical and axillary lymph nodes were slightly enlarged, being discrete and non-tender.

No other lymph nodes were enlarged and the liver and spleen were not palpable. Examination of the chest and abdomen showed nothing abnormal.

Central nervous system examination revealed a bilateral perceptive deafness but no other neurological defects.

Examination of the nose and throat showed thickening of the nasal mucosa.

INVESTIGATIONS

Haematology

Haemoglobin I $\cdot 96$ g./ $100 \mathrm{ml}$. Red blood cells $4 \cdot 9$ million/c. mm. White blood cells $6,000 / \mathrm{c} . \mathrm{mm}$. (neutrophils 74 per cent., eosinophils 6 per cent., lymphocytes 17 per cent., monocytes 3 per cent.). Erythrocyte sedimentation rate (Westergren) $40 \mathrm{~mm}$. Ist hr at $2 \mathrm{yrs}, 8 \mathrm{~mm}$. at i I yrs.

Sternal marrow showed histiocytes with cytoplasmic inclusions consisting of amorphous hyaline debris and nuclear debris. The numbers of histiocytes did not appear to be increased above normal, but a slight increase in lymphocytes, eosinophils, and plasma cells was noted. Chromosome studies on peripheral blood leucocytes were normal.

\section{Biochemistry}

Serum proteins $7 \cdot 82$ g./ 1 oo ml. (albumin $3 \cdot 76$, globulin $4 \cdot 06$, with raised $\alpha_{2}$ and $\gamma$ globulins on electrophoresis).

Serum cholesterol $205 \mathrm{mg}$./ $100 \mathrm{ml}$, , bilirubin $0.3 \mathrm{mg}$./ $100 \mathrm{ml}$., alkaline phosphatase $18.0 \mathrm{~K} . \mathrm{A}$. units/roo ml. Normal urinary amino-acid pattern. 


\section{Bacteriology}

Microscopy and culture of urine normal. Giardia lamblia isolated from the stools on one occasion. Mantoux and Kveim tests negative.

Serological screening for antibodies to a wide range of viruses negative.

\section{Radiology}

$X$-ray studies of the skull, with special projections to examine the orbits and ears, and of the chest and abdomen showed no abnormal features, apart from thickening of the mucosae of the nasal sinuses.

Biopsy excision of the right upper eyelid tumour was done (Fig. 2) and later left lateral tarsorrhaphy was performed to aid lid closure.

PATHOLOGY

\section{Upper eyelid swelling}

The swelling from the right upper eyelid was a smooth firm off-white nodule $1 \mathrm{~cm}$. in diameter. Histologically this consists of lymphoid tissue broken up by bands of dense fibrous tissue and collagen which show an infiltrate of plasma cells and lymphocytes. The lymphoid tissue component is aggregated into follicles (Fig. 3), with well-developed germinal centres in some areas. These lymph follicles are separated by sinusoids filled by proliferating non-neoplastic histiocytes extending into the lymph follicles which are partially broken up in some areas (Fig. 4). There are also moderate numbers of plasma cells and eosinophils in the sinusoids.
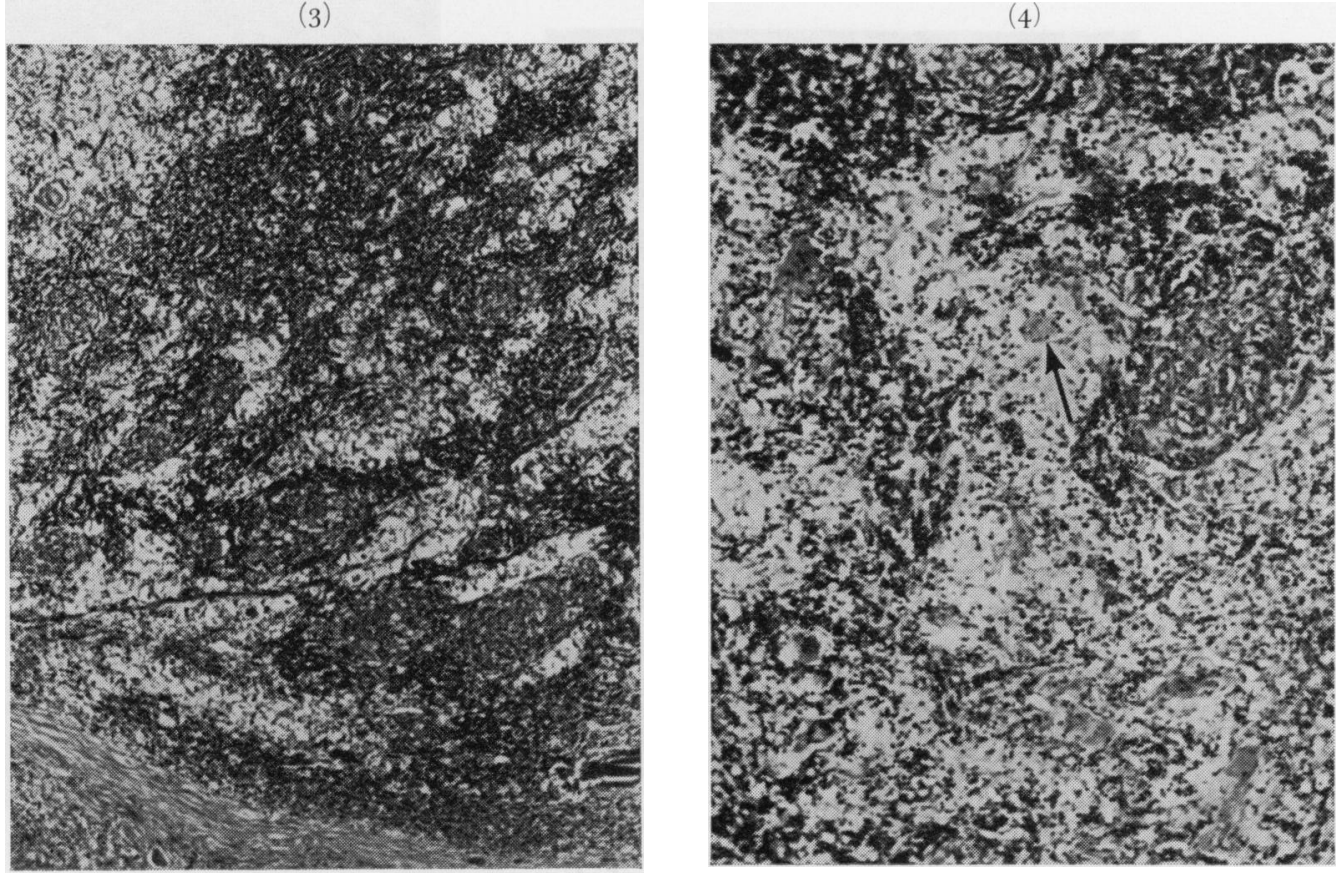

FIG. 3 Low-power view of orbital tumour. Haematoxylin and eosin. $\quad \times 36$

FIG. 4 Partially broken-up lymphoid follicles with intervening sinuses distended by histiocytes, some of which contain phagocytosed cells (arrow). Haematoxylin and eosin. $\quad \times 63$

The histiocytes show large vesicular nuclei with occasional eosinophilic nucleoli, and the nuclei show increased variation in shape and size with occasional bi- and trinucleate forms. The cytoplasm of these cells has a foamy eosinophilic appearance with ill-defined margins and variable-sized vacuoles. Many of the vacuoles contain phagocytosed mononuclear cells (Fig. 5, overleaf) (many 
of which have the characteristics of plasma cells) and red blood cells. Other vacuoles appear empty and on frozen section fat is present, although the amount demonstrated is very small and the distribution irregular.

Comparison with the previous biopsies of 1962 and 1966 showed essentially similar features with increased prominence of the histiocytic component. These features compared most closely with those of Hand-Schüller-Christian disease with the proliferating histiocytes and infiltrate of eosinophils, although there was no evidence of cholesterol crystals in the tissue and the clinical features were atypical. No definitive diagnosis was therefore possible, but the condition was thought to be an atypical form of lipid storage disorder related to Hand-Schüller-Christian disease.

Sections of the orbital swelling were referred to Prof. N. Ashton, who had studied earlier preparations, when the yet undeveloped pattern had suggested to him an inflammatory pseudotumour. The latest biopsy indicated a histiocytosis with insufficient information for characterization and examination of a lymph node was suggested, amongst other investigations.

Dr. L. E. Zimmerman, to whom the material was also referred, had considered the lesion to be benign in 1966 and possibly a xanthogranulomatous reaction. On the latest sections he agreed with Dr. Francis King, with whom he discussed the material, that the condition was an example of a recently described new entity "sinus histiocytosis with massive lymphadenopathy" (Rosai and Dorfman, 1969; vide infra under Discussion).

In view of this a lymph node biopsy was undertaken, and at the same time an examination of the thickened nasal mucosa was also carried out.

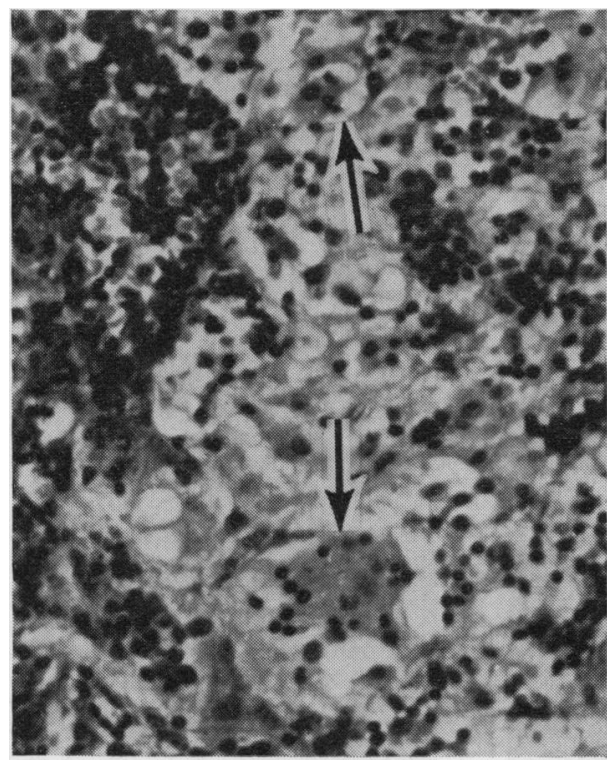

FIG. 5 Area of previous figure at higher magnifcation, showing phagocytosed cells within the cytoplasm of histiocytes (arrows). Haematoxylin and eosin.

$\times 320$

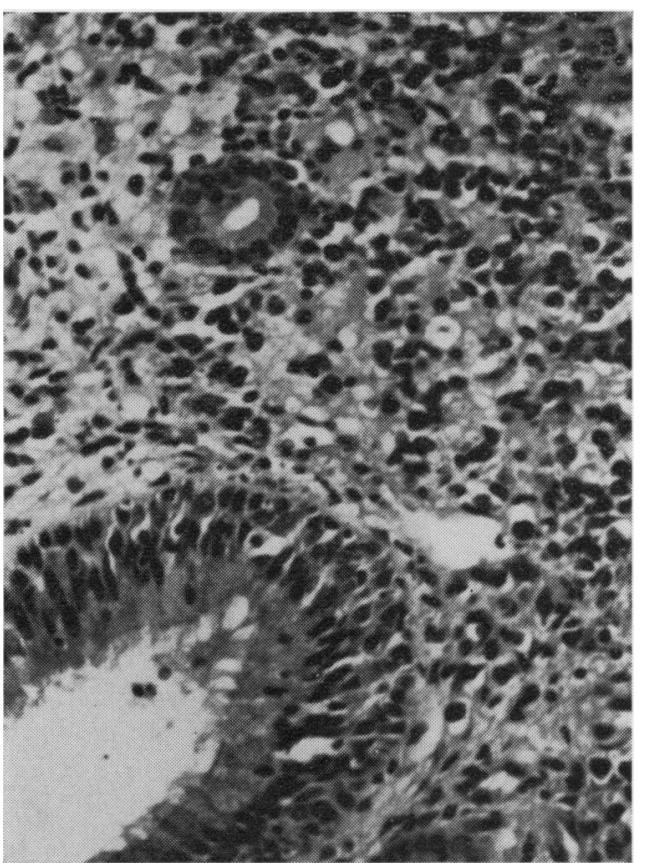

FIG. 6 Nasal biopsy, showing subepithelial infiltrate of histiocytes, plasma cells, and lymphocytes. Haematoxylin and eosin. $\quad \times 320$

\section{Nasal biopsy}

Examination of the nasal biopsy from the left inferior turbinate shows a fragment of tissue lined by normal respiratory epithelium containing mucous glands. Beneath the epithelium the connective tissues show appearances similar to those seen in the orbital tissues with heavy infiltration of histiocytes with eosinophilic foamy cytoplasm. In addition, there is infiltration with plasma cells and lymphocytes (Fig. 6). The histiocytes also show vacuoles containing phagocytosed material. 
(7)

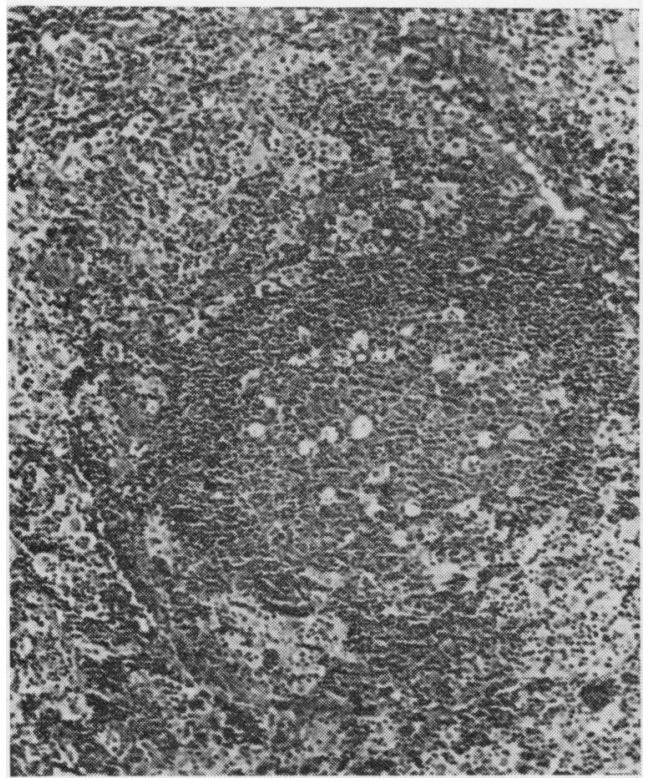

(8)

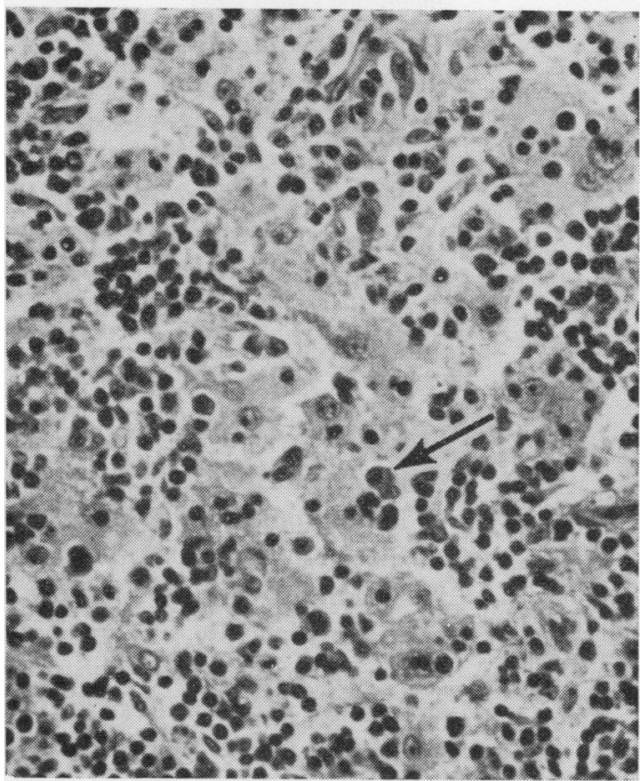

FI G. 7 Submental lymph node showing early destruction of the architecture of a lymphoid follicle by proliferating histiocytes. Haematoxylin and eosin. $\times 63$

FIG. 8 Histiocytes containing phagocytosed cells with in one area a recognizable plasma cell within the cytoplasm of a histiocyte (arrow). Haematoxylin and eosin. $\quad \times 320$

(9)

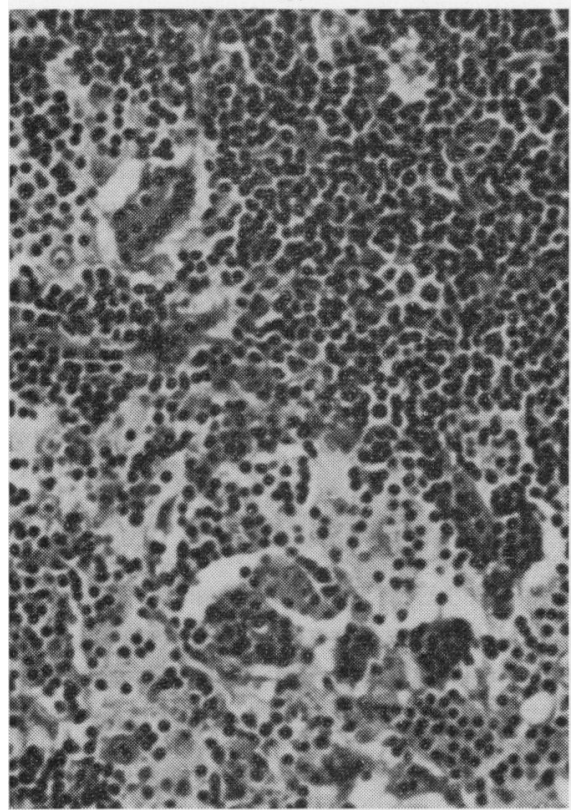

( 10$)$

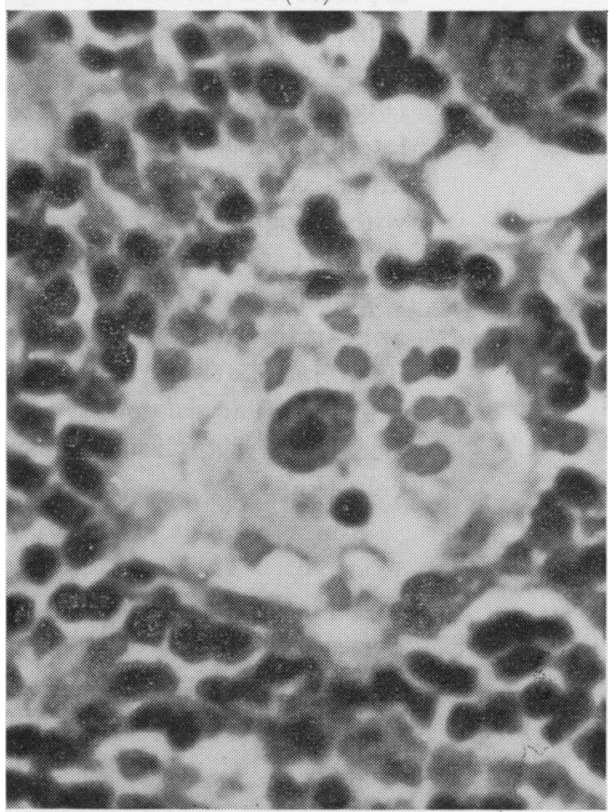

FIG. 9 Histiocytes containing large numbers of plasma cells. Haematoxylin and eosin. $\times 250$

FIG. Io Histiocyte containing phagocytosed red blood cells. Haematoxylin and eosin. $\quad \times 800$ 


\section{Submental lymph node}

This firm white nodule $\mathrm{I} \cdot 5 \mathrm{~cm}$. in diameter shows essentially reactive changes seen as prominent germinal follicles and dilated sinusoids containing accumulations of histiocytes which extend into the germinal centres destroying their architecture (Fig. 7). The histiocytes have similar appearances to those in the orbital biopsy, having an ill-defined cytoplasm with vacuoles containing phagocytosed mononuclear cells, some of which are recognizable as plasma cells (Fig. 8). Some histiocytes show a striking appearance with in excess of ten phagocytosed cells identifiable in their cytoplasm (Fig. 9). Occasional histiocytes also contain phagocytosed red blood cells (Fig. 10) and polymorphonuclear leucocytes. The subcapsular sinusoids are similarly distended by histiocytes and there is a lymphoid and plasma cell infiltrate in the capsule. Occasional eosinophils are also present in the lymph node.

\section{ELECTRON MICROSCOPY}

Orbital tissue for electron microscopy was obtained from the paraffin blocks used for light microscopy.

Tissue from the submental lymph node was obtained fresh and immediately fixed in the operating theatre in buffered Caulfield's osmium tetroxide with a veronal acetate-sucrose buffer and embedded in araldite. Ultrathin sections were cut on a Reichert O.M.2 ultramicrotome, stained with lead and uranyl acetate, and examined on an A.E.I. 8o I electron microscope.

The appearances in the orbital tissue were technically unsatisfactory for critical observation because of previous formalin fixation and paraffin embedding, but showed features consistent with those seen in the lymph node and comparable with the light microscopic findings and will not be described further.

The appearances in the lymph node confirmed the light microscopic findings of sinusoids distended by large numbers of histiocytes, many of which contain phagocytosed cells recognizable in many cases as plasma cells (Figs I I-I 5), red blood cells (Figs I 5, I6, I 7), and occasional polymorphonuclear leucocytes (Fig. 18) in their cytoplasm.

The phagocytosed cells are present within unit membrane bound vacuoles in the cytoplasm and are seen to be at various stages of degradation.

Many of the cells are recognizable as plasma cells, mainly by the large amounts of degenerate rough endoplasmic reticulin within their cytoplasm (Figs II-I4). The nuclear configuration (Fig. II) in some is preserved and degenerate mitochondria (Figs II, I2) are recognizable. In the later phases the cell components are less readily identifiable with condensation of nuclear chromatin into electron dense clumps (Figs I I, I3, I4) and clear areas which represent ballooned mitochondria, with recognizable cristae still present at their edges (Figs II, 12). Also seen are 'myelin figures' (Figs I I-14), which represent phospholipid membrane components resulting from cytoplasmic degradation. At the periphery in many areas the limiting membrane of the phagocytic vacuole appears thickened at low power; at high power this appearance is seen to be due to layering of multiple membranes at the periphery of the vacuole (Fig. 14). Irregular vacuoles filled with dense osmiophilic fibrillary material are interpreted as degraded red blood cells. These are seen both in isolation in the cytoplasm of histiocytes (Figs 16,17 ) and also in association with other phagocytosed cells (Fig. 15).

Intact lymphocytes are occasionally seen within the cytoplasm of the lining cells of sinuses (Fig. 19). This may represent the phenomenon of emperipolesis (Marchesi and Gowans, 1964) or may possibly be artefactual, and due to the plane of sectioning of two closely applied cells. However, occasional cells (probably lymphocytes) showing degenerative changes are seen within vacuoles in histiocytes. These appear as vacuoles with central clear areas and peripheral nuclear chromatin and degenerate cell organelles and membrane systems (Fig. 20).

PROGRESS

After the excision of the right lid tumour and left lateral tarsorrhaphy, lid closure remained inadequate and further treatment was necessary. Radiotherapy was used and a total dose of 2,00o $\mathrm{r}$ was given in divided doses of $100 \mathrm{r}$ in the course of a month. The proptosis gradually receded until at the 


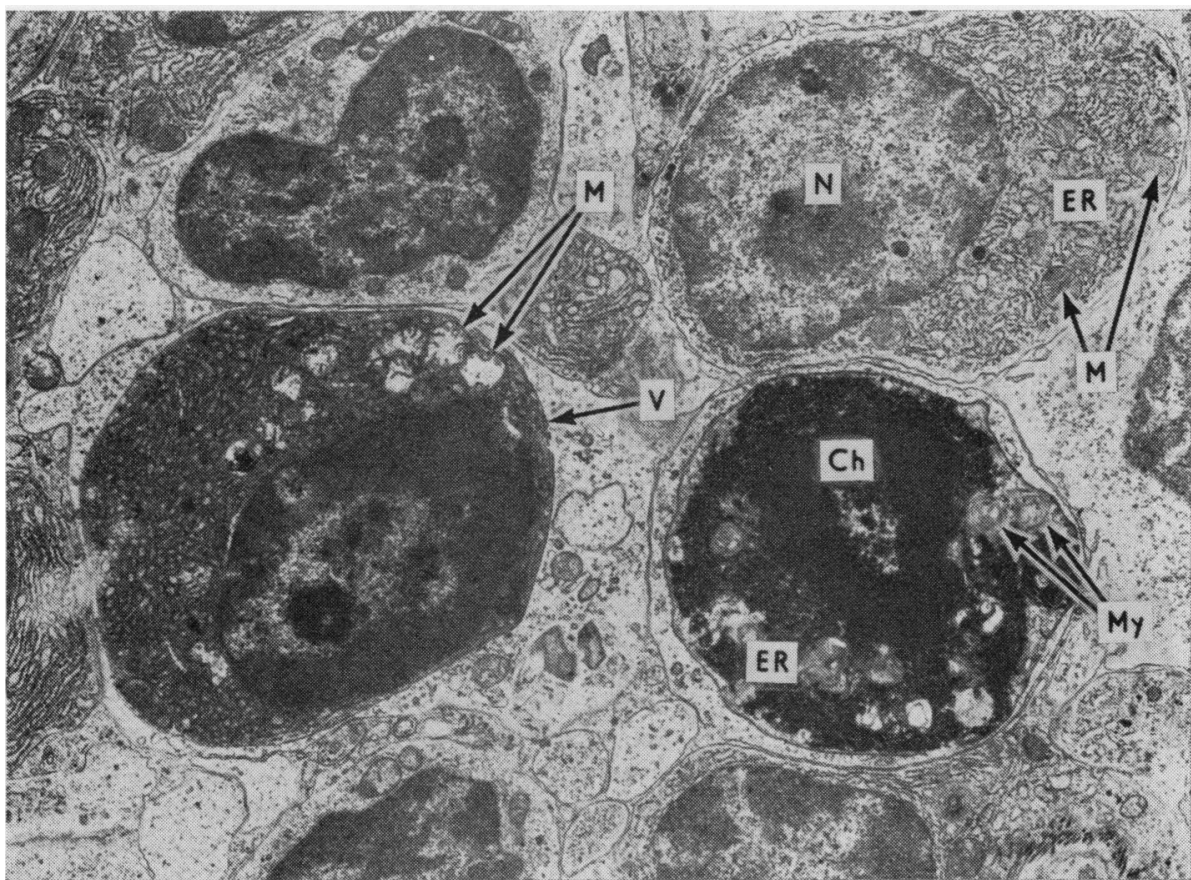

FIG. I I Three plasma cells, two showing degenerative changes and lying within phagocytic vacuoles, and one (top right) is normal. $\mathcal{N}=$ Nucleus. $V=$ Phagocytic vacuole. $M=$ Mitochondria. $\quad C h=$ Condensed nuclear chromatin. $\quad E R=$ Endoplasmic reticulum. $\quad M y=$ Myelin figures. $\quad \times 6,300$

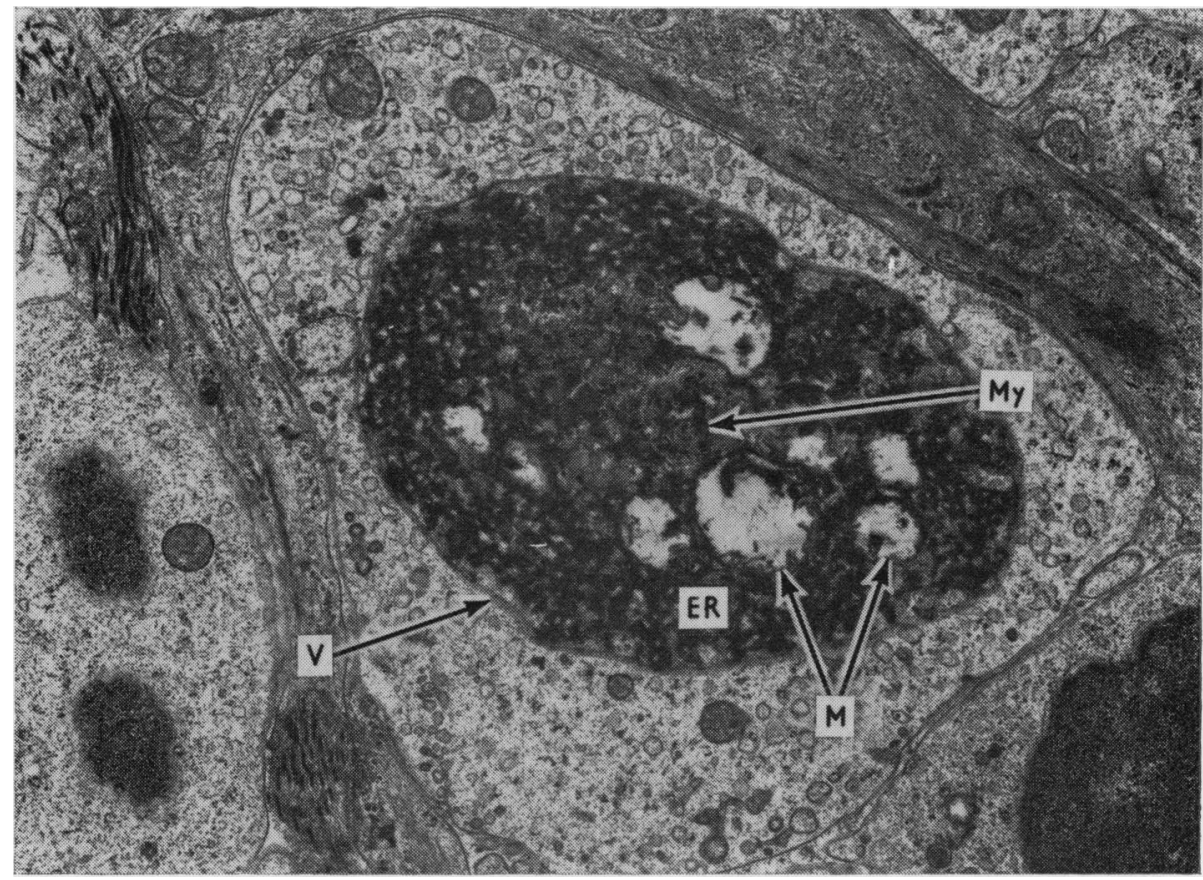

FIG. I2 Phagocytosed plasma cell within a vacuole $(V)$, showing degenerate endoplasmic reticulum (ER), ballooned mitochondria $(M)$, and early myelin figures $(M y) . \quad \times 11,000$ 


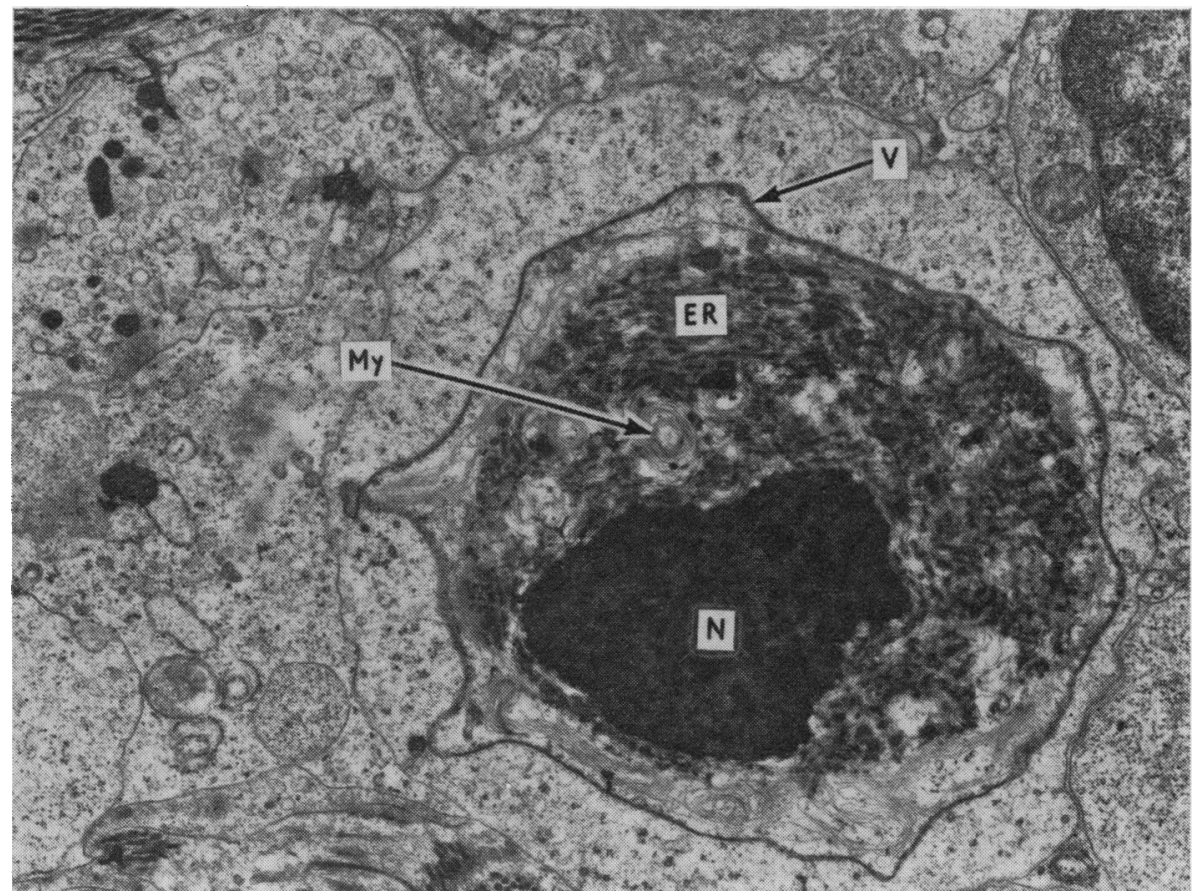

FIG. I3 Degradation of a phagocytosed plasma cell lying in a vacuole $(V)$ showing a crenated outline. $\mathcal{N}=$ Nucleus. $\quad M y=$ Myelin figure. $\quad$ Er $=$ Endoplasmic reticulum. $\quad \times 12,200$

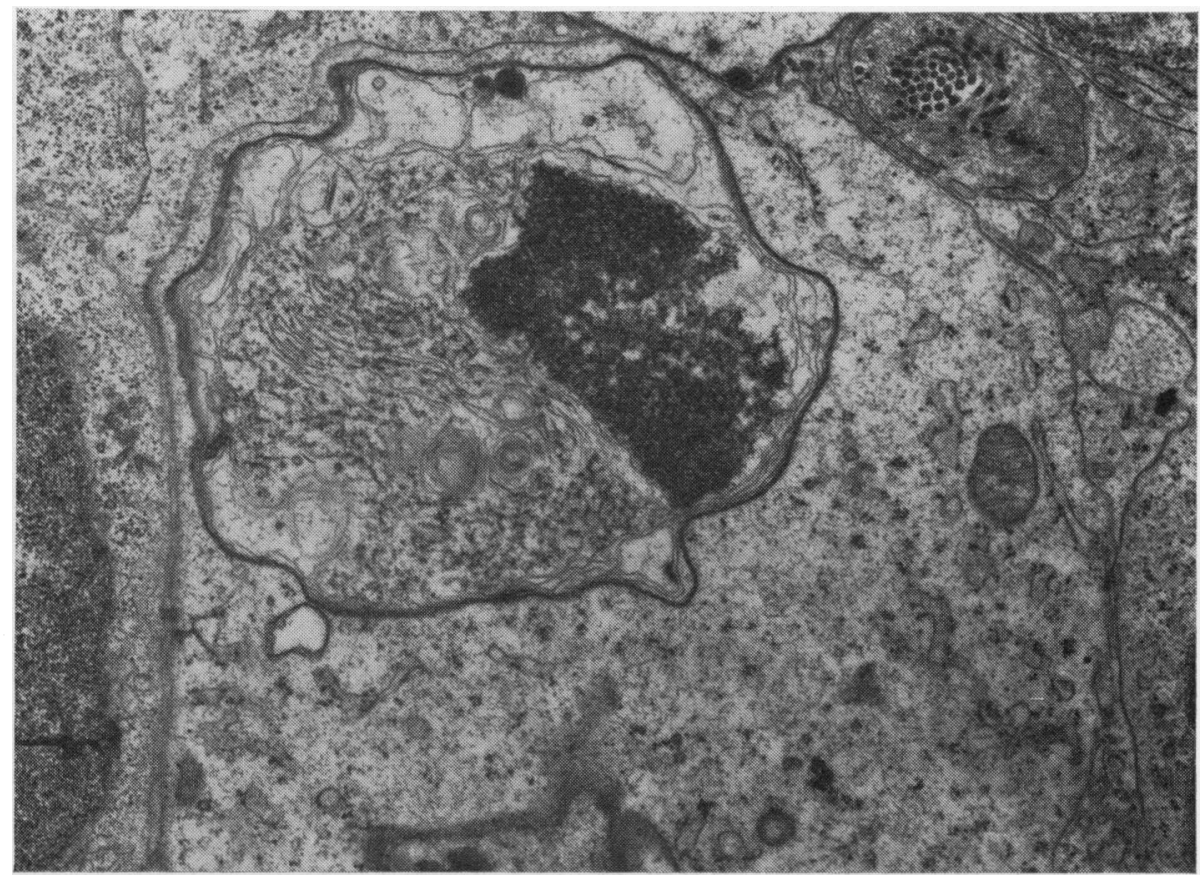

FIG. I4 Late stage of degradation of a phagocytosed cell in an irregular-shaped vacuole with clear areas at the periphery and condensation of membrane at the edge of the vacuole, giving the limiting membrane a thicker appearance than those seen in earlier stages. $\times 16,700$ 


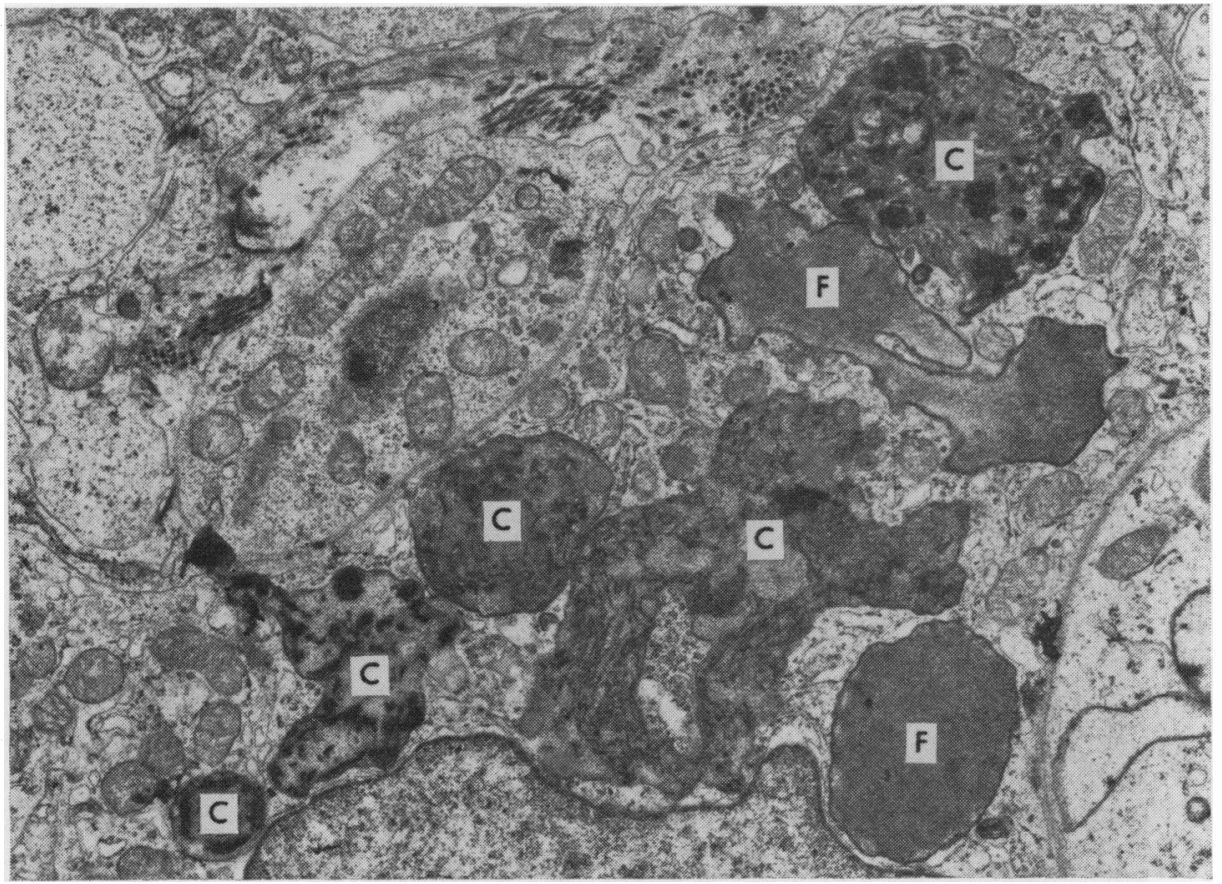

FIG. I5 Part of a histiocyte with many phagocytic vacuoles in the cytoplasm some of which contain degenerate cells $(C)$ recognized by degenerate mitochondria and endoplasmic reticulum. Other vacuoles contain fine fibrillary material $(F)$ possibly the remains of red blood cells. $\quad \times 10,800$

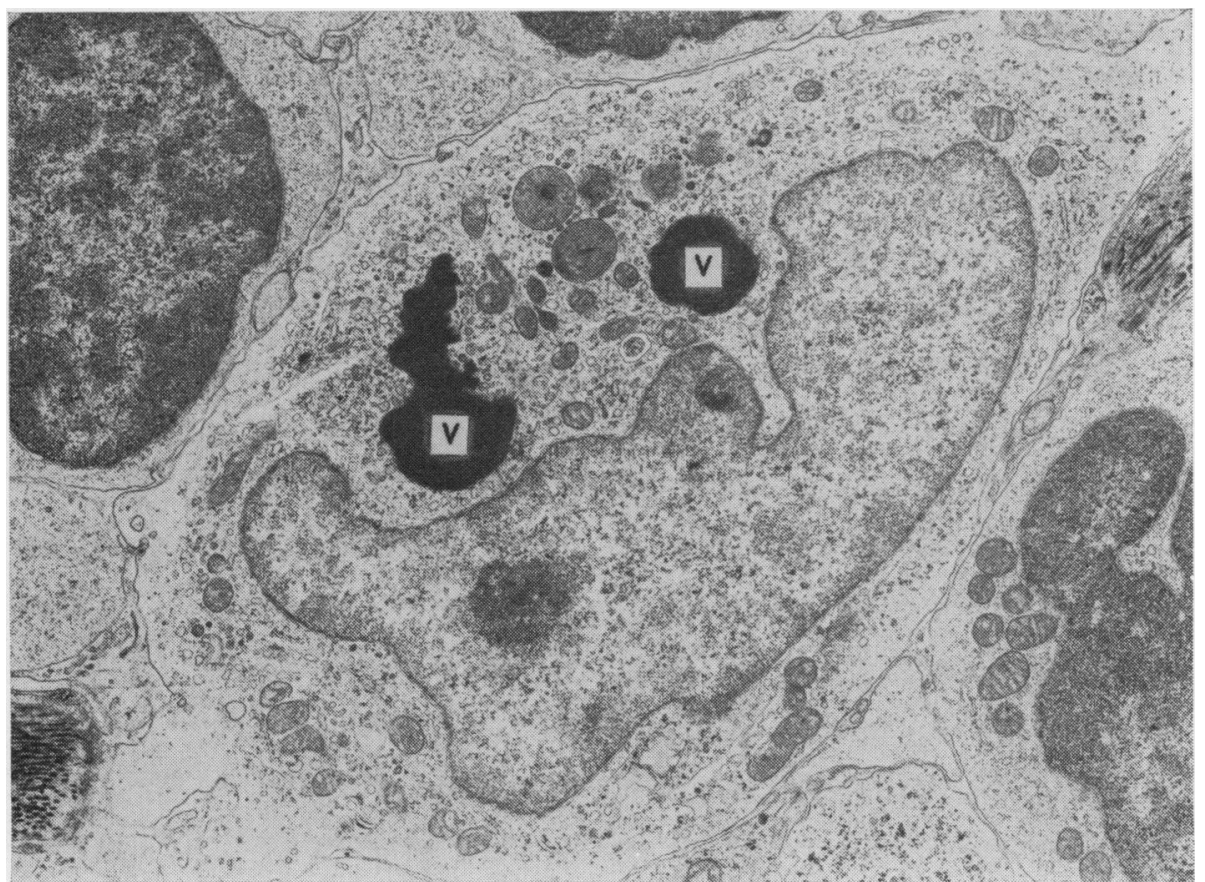

F I G. I6 Two darkly staining vacuoles $(V)$ in the cytoplasm of a histiocyte. These contain uniform fine fibrillary material and are interpreted as being of red cell origin. $\quad \times 8,000$ 


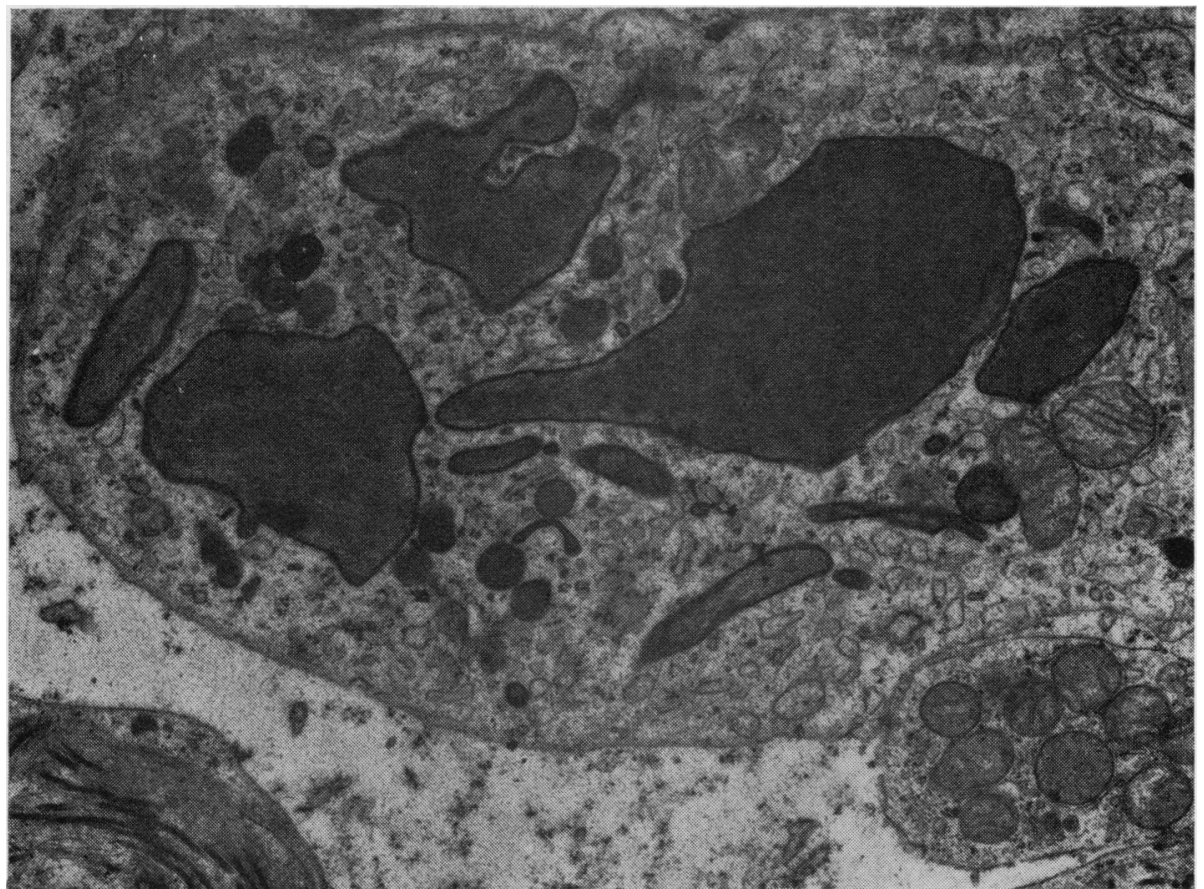

FIG. I 7 Multiple vacuoles in the cytoplasm of a histiocyte showing a fine fibrillary structure interpreted as of red cell origin. $\times 14,500$

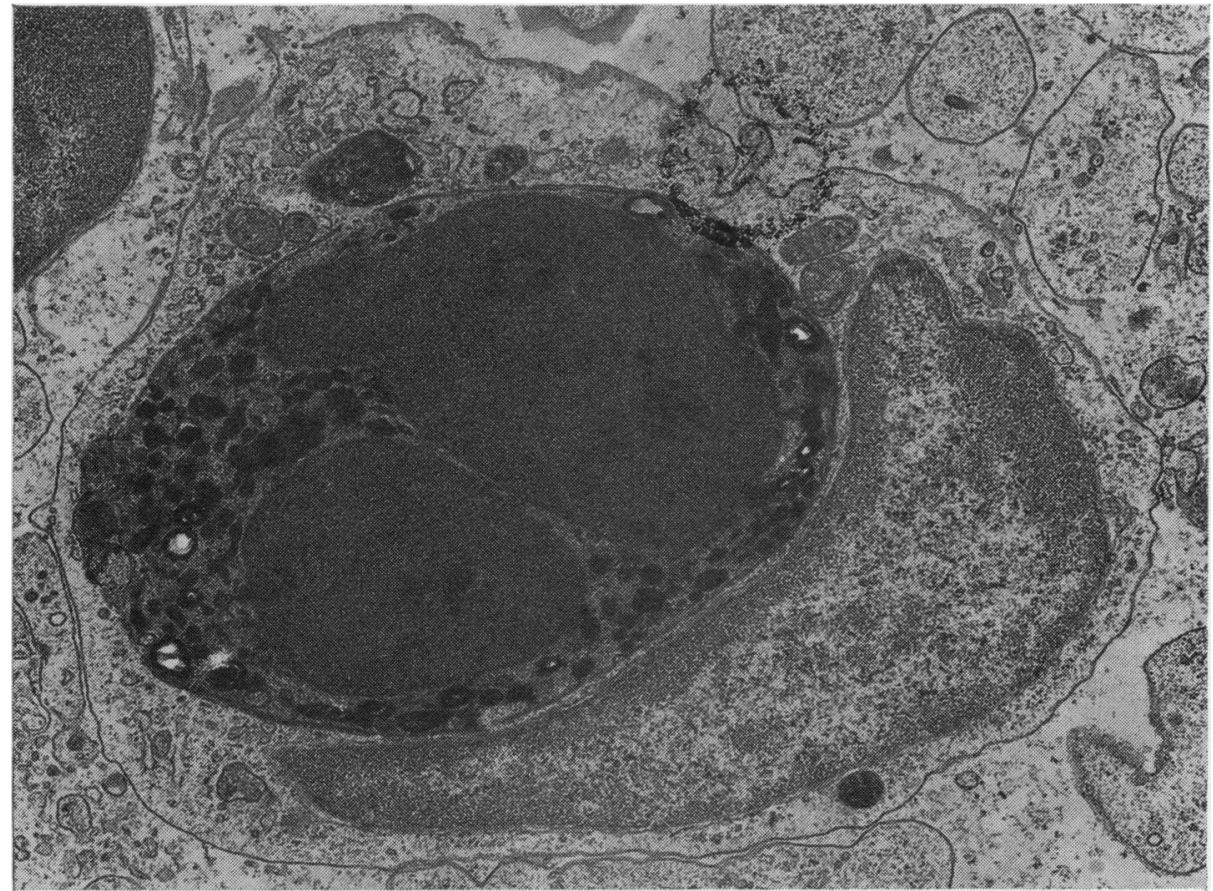

FIG. I8 A polymorphonuclear leucocyte showing early degenerative changes within a cytoplasmic vacuole of a histiocyte. $\quad \times 1 \mathrm{I}, 000$ 


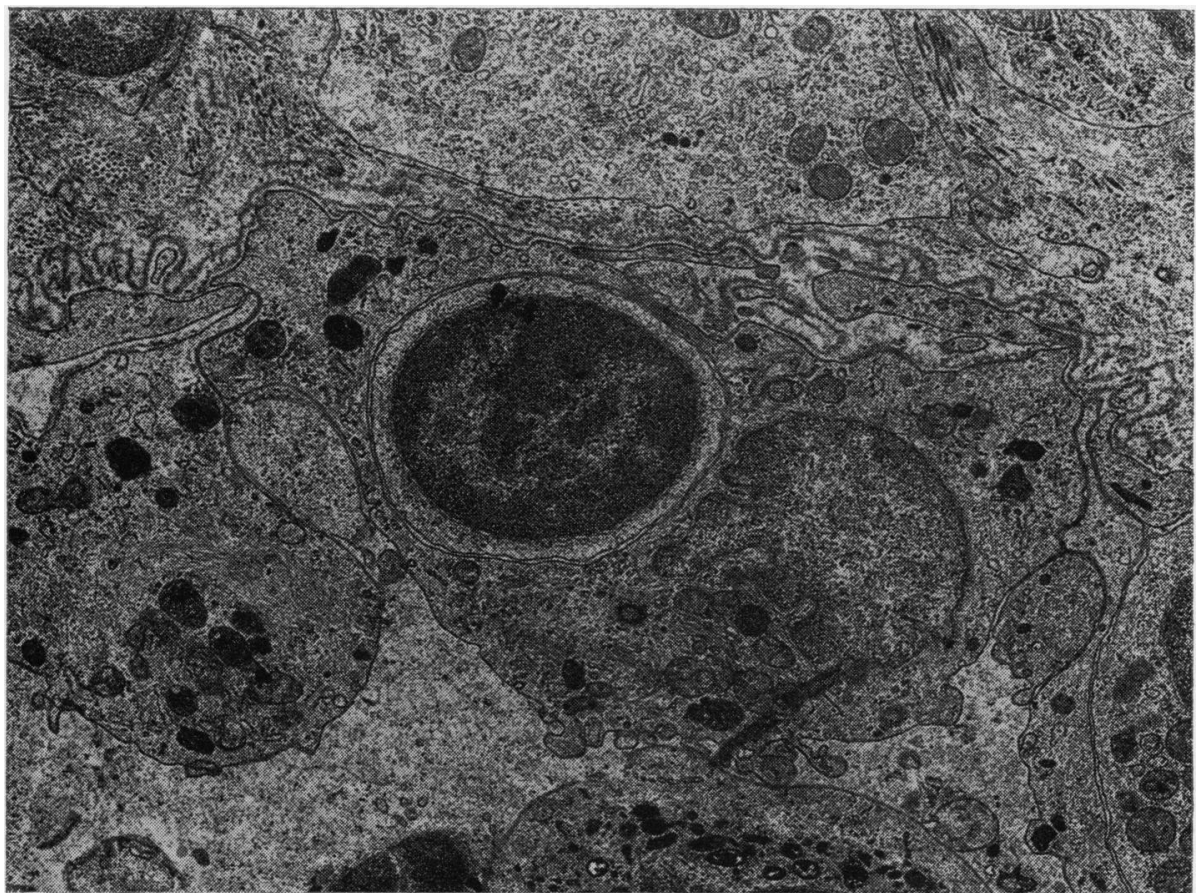

FIG. 19 Intact lymphocyte within the cytoplasm of a sinusoidal lining cell. $\quad \times 9,200$

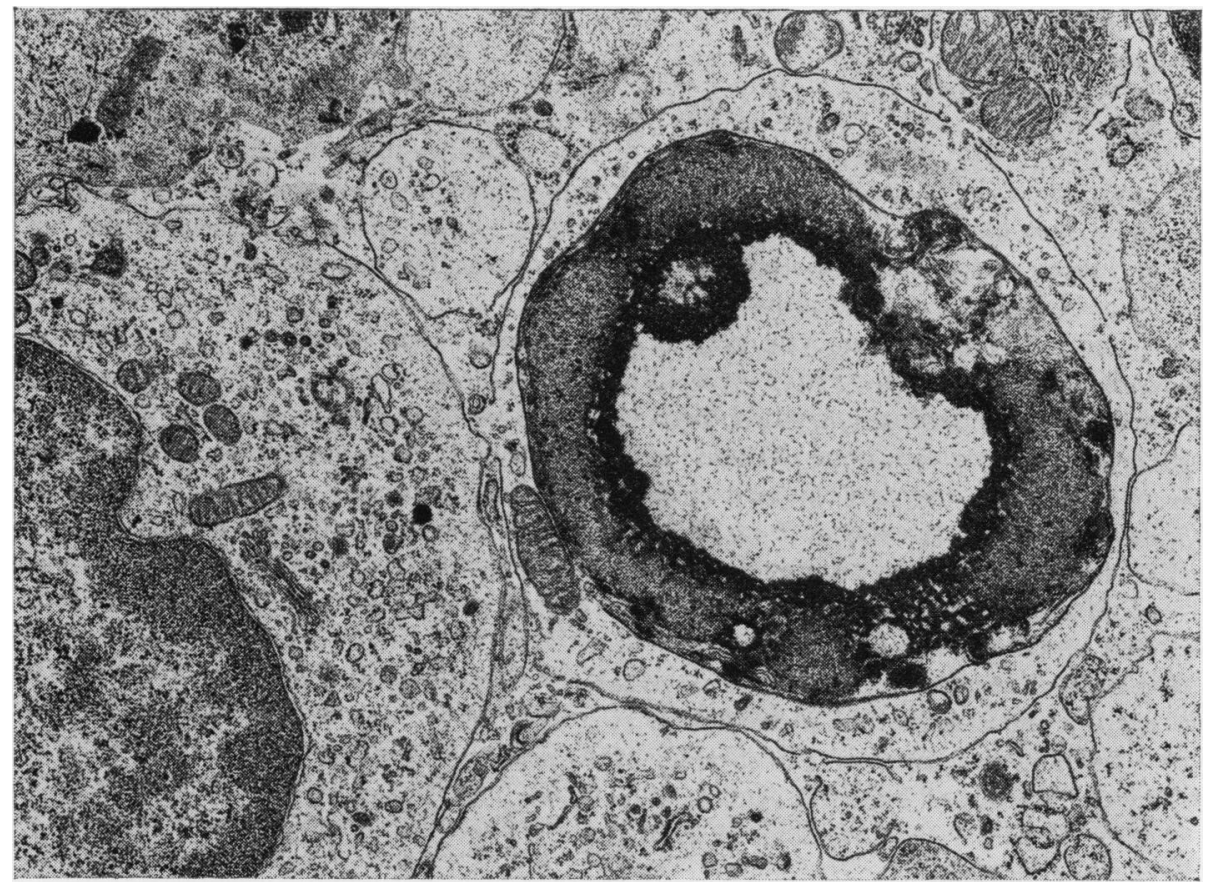

FIG. 20 Degenerate cell, probably of lymphocyte origin, undergoing destruction, showing a clear central area and peripheral darkly staining zone within a cytoplasmic vacuole. $\quad \times 11,000$ 
end of treatment the Hertel Exophthalmometer readings were right $18 \mathrm{~mm}$. and left $20 \mathrm{~mm}$. (Fig. $2 \mathrm{I}$ ).

At this stage lid closure was adequate and the nasal mucosal thickening had diminished, but the deafness had not improved.

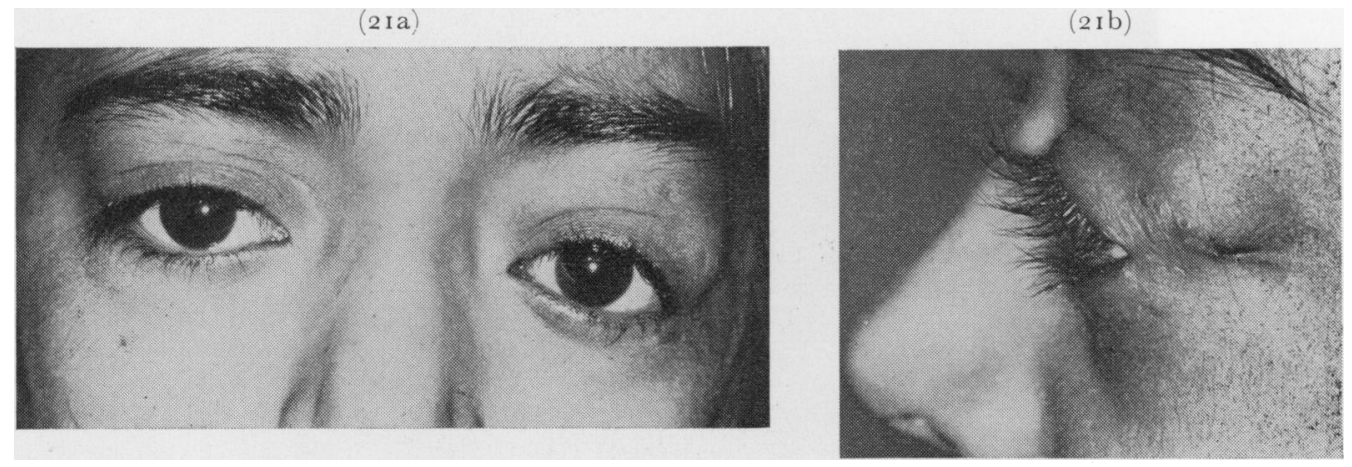

FIG. 2 I $(a, b)$ Frontal and lateral post-radiotherapy clinical photographs, showing reduction of proptosis and eyelid swellings.

\section{POSTIRRADIATION BIOPSY}

A further biopsy from the orbit at this stage consisted of fat and fibrous tissue macroscopically. Histologically the fibrous tissue showed a dense cellular infiltrate of lymphocytes and plasma cells with some histiocytes. The histiocytic component was greatly reduced; only occasional foamy histiocytes containing phagocytosed cells and debris were now present compared with their previous predominance. The condition remained static for a follow-up period of 6 months after which the patient left for Pakistan. The last report from Pakistan in February, 197I, indicates that it is still unchanged.

\section{Discussion}

The features of this case are unlike those of any of the previously recognized reticulo-endothelial disorders. The differential diagnosis of this entity includes a wide variety of disease processes. Lymphoma, in particular histiocytic lymphoma and histiocytic medullary reticulosis (Rappaport, 1966), are excluded histologically by the nature of the histiocytic proliferation which is confined to sinuses, and by the lack of atypicality of the histiocytes, and also clinically by the chronicity of the lesions in an otherwise healthy child.

Familial haemophagocytic reticulosis (Marrian and Sanerkin, 1963) and familial reticuloendotheliosis (Omenn, 1965) typically show hepatosplenomegaly, anaemia, leucopenia, failure to thrive, and prominent erythrophagocytosis by histiocytes. Apart from occasional cells showing erythrophagocytosis, none of these features are seen in the present case.

The storage disorders can be excluded in view of the absence of lipid or mucopolysaccharide in the cytoplasm of histiocytes both on light microscopy and at the ultrastructural level.

Nonspecific reactive hyperplasia is excluded by the florid progressive nature of the histiocytic proliferation associated with a prominent degree of phagocytosis of other cells, particularly plasma cells by these histiocytes.

Orbital pseudotumour, which may cause bilateral proptosis, histologically presents a very varied picture and is unlike the present case.

Juvenile xanthogranuloma (Staple, McAlister, Saunders, and Miller, 1964) is excluded clinically by the absence of bone destruction, skin lesions, or iris tumours, and histologically by the absence of focal nodular accumulations of the foamy histiocytes and Touton type giant cells which are typical of this condition.

The absence of hepatosplenomegaly, skin lesions, and anaemia, along with the relatively benign course of the present case, differentiates it from Letterer-Siwe disease. Also at an ultrastructural 
level (Shamoto, 1970) the demonstration of Langerhans cell granules further aids differentiation, since these were not found in the case under discussion.

Hand-Schüller-Christian disease shows many similarities to the present case both in the clinical presentation and histologically.

Clinically, the presence of proptosis, deafness, and lymphadenopathy are consistent with this diagnosis even in the absence of bony lesions, diabetes insipidus, hepatosplenomegaly, and skin lesions which are also components though not essential for the diagnosis (Avery, McAfee, and Guild, 1957). Histologically, the proliferation of abnormal vacuolated histiocytes with infiltration of eosinophils in the lymphoid tissue are again consistent with this. However, the failure to demonstrate cholesterol crystals in the lesion are against the diagnosis. The ultrastructural features (Imamura and Muroya, 197 I) are also dissimilar and the failure to demonstrate the typical rod-like inclusions seen in the histiocytes of the 'Histiocytosis X' group of disorders (de Man, I968) are also against this diagnosis.

The present case also shows many similarities to the recently described entity of sinus histiocytosis with massive lymphadenopathy (Rosai and Dorfman, 1969).

Four cases of this condition were described. It presented in patients between the ages of 7 months and 20 years as painless cervical lymphadenopathy of insidious onset with pyrexia in the early phases, leucocytosis, and hypergammaglobulinaemia. Two further cases from the literature were reviewed and considered to be the same condition. One of these patients (Vincent and Miercourt, 1967) presented with eyelid swellings and nasal polypi in addition to massive cervical lymphadenopathy. In contrast to our patient, the lymphadenopathy was a prominent feature and nasal polypi rather than mucosal thickening were present. In addition, deafness and a positive family history were not described as features of this case or of the four cases of Rosai and Dorfman. Histologically, there was an abnormal proliferation of histiocytes; these occurred at first within the sinuses of lymphoid tissue but eventually led to destruction of the normal architecture of the follicles. The histiocytes had vesicular nuclei with prominent nucleoli and ill-defined cytoplasm with vacuoles containing phagocytosed lymphocytes and occasional polymorphs and red blood cells.

In our case the mononuclear phagocytosed cells in the cytoplasm of histiocytes were interpreted initially as plasma cells and lymphocytes, but the latter proved to be degenerate plasma cells apart from occasional intact lymphocytes and occasional possible degenerate lymphocytes in the cytoplasm of histiocytes.

\section{AETIOLOGY AND TREATMENT}

The aetiology of this condition is unknown and speculation regarding possible mechanisms includes an inherited autosomal recessive defect in autologous cell recognition affecting plasma cells.

The plasma cells recently phagocytosed show no features to suggest a morphological basis for a defect.

Since, however, cell recognition depends to a certain extent on cell membrane composition at a molecular level, and since not all plasma cells are undergoing phagocytosis, it may be postulated that there is a membrane defect which becomes apparent with ageing and which predisposes to phagocytosis by histiocytes.

Since the aetiology of this condition is unknown, the treatment must be purely empirical and possible alternatives are local excision, chemotherapy, and localized radiotherapy.

Surgical excision was unlikely to be effective since recurrences had developed following previous excisions and also because total excision of involved tissue would have been technically impossible. Chemotherapy has been used to treat the disseminated lesions of Letterer-Siwe and Hand-SchüllerChristian disease (Mermann and Dargeon, 1955), but in the present case this was not used since lesions causing symptoms were confined to eyelids and orbit. It was therefore felt unjustifiable to use a systemic therapy with the risk of widespread toxic effects.

Local radiotherapy has been used successfully in the control of localized lesions such as exophthalmos in Hand-Schüller-Christian disease (Mermann and Dargeon, 1955). This treatment, in twenty 
divided doses of too $\mathrm{r}$ each, was used in our patient, since without treatment she would almost certainly have developed exposure keratitis.

The treatment proved effective in shrinking the lesions by the destruction of lymphoid tissue and inō particular the histiocyte component. There has been no evidence of recurrence after 6 months.

\section{Summary}

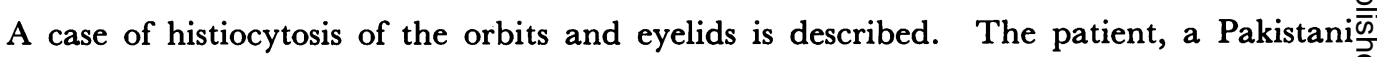
girl, first presented at the age of 3 years with eyelid swellings, which were excised with subsequent recurrence and further excision at the age of 7 years. At the age of I I therew was a further recurrence of the eyelid swellings, and deafness and slight enlargement of the $\vec{\circ}$ cervical and axillary lymph nodes were noted for the first time. The patient's grandmother $\overrightarrow{\vec{\omega}}$ and paternal uncle had had similar eyelid swellings and deafness. Investigation revealed ${ }_{\sigma}^{\omega}$ raised alpha 2 and gamma globulins. Bone marrow, and orbital, nasal, and lymph node 0 biopsy on light microscopy show abnormal proliferation of vacuolated histiocytes con-\% taining phagocytosed cells. These features were confirmed by electron microscopy of the lymph node biopsy. Treatment with deep $x$-ray therapy to the orbital swellings has been successful in reducing the size of the swelling and the post-irradiation biopsyo shows fibrous tissue infiltrated by plasma cells and lymphocytes and a striking reductionof the histiocyte component of the swelling.

The possible diagnosis of this condition, its similarity to the recently described clinico-pathological entity of sinus histiocytosis with massive lymphadenopathy, and possible pathogenic mechanisms are discussed.

Our thanks are due to Prof. N. Ashton, Department of Pathology, Institute of Ophthalmology, London, Dr. Francis King, Chief of the Reticulo-Endothelial Branch of the Armed Forces Institute of Pathology, Washington D.C., Dr. D. H. Wright, Department of Pathology; University of Birmingham, and Dr. L. E. Zimmerman, Chief of the Ophthalmic Branch of the Armed Forces Institute of Pathology, Washington D.C. $\stackrel{\varrho}{\longrightarrow}$ for their opinions on the light microscopic material, and to Miss G. L. Parkinson for her secretarial assistance.

\section{References}

AVERy, M. E., McAfee, J. G., and Guild, H. G. (1957) Amer. J. Med., 22, $6{ }_{3} 6$

DE MAN, J. C. H. (I968) J. Path. Bact., 95, 123

imAMURA, M., and MUROYA, K. (197I) Cancer, 27, 956

MARchesi, v. T., and gowans, J. L. (1964) Proc. roy. Soc. B, 159, 283

MARrian, v. J., and SANERkin, N. G. (1963) J. clin. Path., 16, 65

MERMANN, A. C., and DARgeON, H. W. (1955) Cancer, 8, 112

omenn, G. s. (1965) New Engl. F. Med., 273, 427

RAPPAPORT, H. (1966) "Tumors of the Hematopoietic System", in "Atlas of Tumor Pathology", N

Section III, fasc. 8. Armed Forces Institute of Pathology, Washington

rosai, J., and Dorfman, R. F. (1969) Arch. Path., 87, 63

SHAMOTO, M. (1970) Cancer, 26, I 102

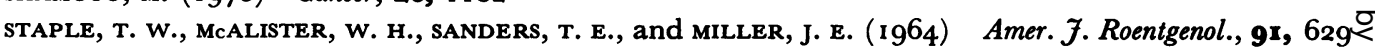

vincent, T. N., and miercort, R. (1967) "Eighteenth Seminar of the Penrose Cancer Hospital,

Colorado Springs, Fall, I966", 3, 246 